\title{
Razones para introducir el concepto de valor empresa en la Ley General de Sociedades
}

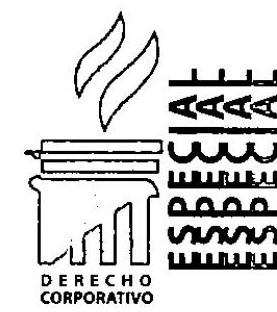

\section{OSWALDO HUNDSKOPf EXEBIO}

Abogado por la Pontificia Universidad Católica del Perú. Profesor de Derecho Comercial en la Universidad de Lima. Miembro del Consejo Consultivo de la Revista ADVOCATUS.

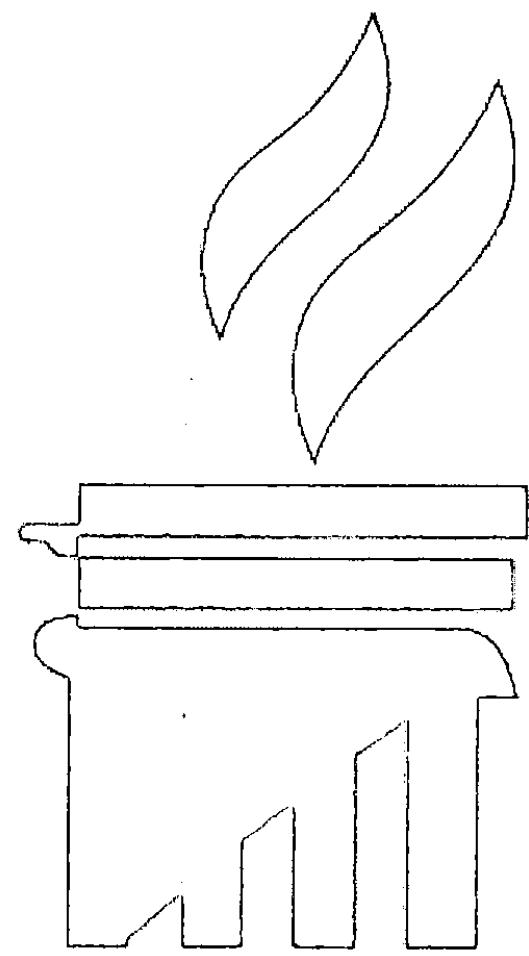

SUMARI0:

I. Introducción.

II. El valor empresa y su reconocimiento en la LGS.

III. Criterios o métodos para la valorización de empresas y su regulación por la LGS.

IV. Propuesta de artículo sustitutorio. 


\section{INTRODUCCIÓN}

Después de haberse cumplido los diez (10) primeros años de plena vigencia de la Ley General de Sociedades, Ley 26887, en adelante LGS, ya es pertinente y oportuno reflexionar críticamente acerca del contenido de tan importante norma legal, y en razón a que ya se tiene una experiencia de su aplicación práctica en la esfera privada propia de las sociedades civiles o mercantiles, además de una casuística acumulada a lo largo de dicho periodo, expresada en resoluciones del Tribunal Registral, o en sentencias judiciales, laudos arbitrales y resoluciones casatorias de la Corte Suprema, ya es posible identificar los defectos, vacíos e imprecisiones de tan importante cuerpo legal. Al respecto, es una constante que toda ley es perfectible y por ende, susceptible de mejorarse, y ese es el propósito que nos debe impulsar, no solo a quienes tuvimos la oportunidad de formar parte de la Comisión Especial encargada de elaborar el anteproyecto y aún, seguimos ejerciendo el Derecho Societario, sino también a los especialistas y docentes de esta importante especialidad.

Siempre en la línea de considerar como una premisa básica que las enmiendas que se propongan, deberían respetar en lo posible la estructura de la LGS y básicamente sustituir artículos específicos, el primer tema que identificamos dentro de una sustanciosa lista', es el relacionado al capital social y a la necesidad de definir el concepto del patrimonio neto, as como el concepto de valor empresa, y como consecuencia de ello, evaluar si es conveniente o no regular en la LGS los principales criterios de valorización de sociedades, o al menos precisar los lineamientos básicos que se deben tomar en cuenta para realizar dicha labor.

Como bien se puede apreciar, es en el artículo 31 de la LGS donde se regula el patrimonio social, y sin definirlo conceptualmente, en él se señala que este responderá por las obligaciones de la sociedad, sin perjuicio de la responsabilidad personal de los socios en aquellas formas societarias que así lo permiten, siendo esta última parte del artículo, de aplicación exclusiva a las formas societarias de responsabilidad ilimitada. Es el caso que la regulación del capital social, que es uno de los elementos indispensables e insustituibles del patrimonio social, y la continua, permanente y necesaria relación y/o contrastación que debe hacerse entre el capital social y el patrimonio neto, y en casos necesarios, la contrastación de ambos con el denominado valor empresa, debe hacerse necesariamente sobre la base del mencionado artículo 31, el cual en nuestra opinión es el que debería ser sustituido por un texto que contemple todos estos conceptos, y por ello, como corolario del presente trabajo, nos permitiremos hacer una propuesta concreta, y formularemos un proyecto de texto sustitutorio del referido artículo.

Consideramos importante precisar además, que el enfoque del presente trabajo lo haremos pensando básicamente en la sociedad anónima, que es la forma societaria mayoritariamente utilizada en los principales proyectos de los diferentes sectores económicos, y que sin duda, por sus características y particularidades, es la modalidad societaria preferida por los inversionistas nacionales y extranjeros, y a la que la propia LGS ha priorizado al regularla, en su libro II, en forma independiente y amplia.

Respecto al capital social, no solo existe una clara regulación en la LGS, sino que además hay una profusa e interesante doctrina nacional y extranjera, tanto acerca de sus principios ordenadores $y / 0$ reguladores, como sobre sus funciones específicas, así como una interesante casuistica, la misma que se puede apreciar a través de resoluciones del Tribunal Registral y de sentencias casatorias de la Corte Suprema de la República referidas directa o indirectamente a dicho concepto.

1 HUNDSKOPF EXEB1O, Oswaldo, Reflexiones sobre la Ley General de Sociedades, a los 10 años de su vigencia. En: Actualidad Juridica, Tomo 171, Gaceta Jurídica, Lima-Perú, febrero de 2008, p. 287. 
En lo que se refiere al patrimonio neto, al cual también podríamos llamar patrimonio líquido, por tener ambas acepciones, según el Diccionario de la Lengua Española, igual significado, este viene a ser el resultado de restar al monto total de los activos verificados y valorizados de una determinada sociedad, el monto total de los pasivos debidamente comprobados y certificados, contraídos por la sociedad frente a terceros, es decir los pasivos exigibles, constituyendo la diferencia, el valor neto del patrimonio, en una fecha determinada.

Después de las precisiones efectuadas, podemos destacar que el patrimonio social es estático y genérico, y que se refiere a una universalidad de activos y pasivos, que el capital social a su vez, es una cifra estática determinada en el pacto social y en el estatuto, cifra a la que se le aplica entre otros, el principio de estabilidad o permanencia, y que, sin embargo, el concepto de patrimonio neto viene a ser un concepto dinámico, mutable, susceptible de variación día a día en función del incremento o reducción de los pasivos frente a terceros, y que, si fuere el caso de que el monto de los pasivos exigibles llegara a superar el monto de los activos, estaríamos frente a una sociedad anónima con patrimonio negativo, afectándose incluso la integridad del capital social, que por ser una cifra del pasivo, constituye una deuda de la sociedad frente a los accionistas. En caso contrario; es decir si el monto de los pasivos resultara inferior al monto de los activos, lo que queda, viene a constituir el patrimonio neto positivo, el cual se muestra en el pasivo del balance, a continuación de la cuenta del capital social, expresándose en cuentas patrimoniales independientes, los beneficios, y/o utilidades, las reservas legales y voluntarias, las primas, los excedentes $y$, en general, todo aquello que la sociedad ha acumulado gracias a un desarrollo exitoso. Si bien tales cuentas de patrimonio se presentan en el pasivo del balance, las mismas se reflejan en la masa general del activo y benefician a todos los accionistas, quienes son en definitiva los acreedores especiales de la sociedad y no obstante ser acreedores subsidiarios y de último rango, y que sus derechos de acreedor no están sujetos a ningún tipo de condicionamiento de plazo, modo tiempo o lugar, serán ellos los que recibirán los beneficios de la distribución del haber social o remanente social, en caso de liquidación de la sociedad.

Ahora bien, en los casos de sociedades con patrimonio neto negativo por incidencia directa de las pérdidas, es necesario tomar de inmediato las decisiones necesarias para reestablecer el equilibrio, lo cual se logrará cuando se reduzca el capital y se anule la pérdida sacrificando parte del capital social, o con nuevos aportes de accionistas $y / o$ terceros. En el caso de patrimonio neto positivo, si la sociedad tuviera que liquidarse y que al final del proceso correspondiente, luego de haberse cancelado todos los adeudos de la sociedad a los acreedores no accionistas (terceros), quedara un remanente o patrimonio neto, en aplicación del artículo 420 de la LGS, este deberá ser distribuido entre los accionistas, con arreglo a las normas establecidas por la ley, el estatuto social y los convenios entre los accionistas inscritos en la sociedad y, en ausencia de reglas especiales, la distribución se deberá realizar en proporción a la participación de cada accionista en el capital social.

Respecto al concepto de patrimonio neto, que es un concepto económico financiero y contable con implicancias legales, está estrechamente vinculado al capital social, pero a diferencia de este, que es una cifra que está establecida en el pacto social, en el estatuto y en la ficha registral, y que por ello se puede conocer de inmediato, su determinación implica todo un procedimiento de análisis propio de los especialistas, que toma varios días o semanas, dependiendo de la complejidad de la situación económica y financiera de la sociedad. No obstante ello, en la LGS existen menciones expresas de dicho concepto, concretamente en los artículos 95,96 , 181, 200, 216 inciso segundo, 218, 230, 305, 407, inciso cuarto y 419 , cada uno de los cuales ha sido comentado anteriormente en un trabajo anterior ${ }^{2}$, en el cual pusimos especial énfasis en

2 HUNDSKOPF EXEBIO, Oswaldo, Apuntes sobre la relación capital social y patrimonio neto. En: Derecho Comercial, Tomo IV, Fondo Editorial de la Universidad de Lima, Lima, 2003. 
la continua y permanente contrastación que se deberá hacer entre el capital social y patrimonio neto. Tal contrastación se apreciará a través de un estado financiero no tomado en cuenta en la Cuarta Disposición Final de la LGS, que se denomina Estado de Cambios en el Patrimonio Neto, y que le servirá al directorio, dada su calidad de organismo técnico de la sociedad, para conocer la situación económica de la misma a una fecha determinada, y en base a ello tomar las decisiones mas convenientes. Es claro que si el patrimonio neto es mayor que el capital social o más alto cuantitativamente, la situación irá desde una situación equilibrada, hasta niveles óptimos de solidez y solvencia, y si es menor que el capital social habrá que estar atento a sí se configura el supuesto de reducción obligatoria del capital social por efecto de las pérdidas a que se refiere el artículo 220 de la LGS, o la causal de disolución prevista en el inciso 4 del artículo 407.

Habiéndose apreciado, la importancia que la LGS le da al patrimonio neto de la sociedad anónima, una vez determinado como producto del análisis económico financiero, podemos conocer el valor en libros de las acciones de la sociedad anónima como resultado de dividir la cifra obtenida entre el número de acciones ${ }^{3}$, valor que diferirá del valor nominal que, como se sabe, resulta de dividir el capital social entre el número de acciones. Serán ambos valores, importantes referentes en las transacciones $u$ operaciones que tengan implicancia con las acciones de la sociedad anónima, y coadyuvarán a la determinación del precio de transferencia de las acciones.

Interesa de manera especial detenernos en el caso del inciso 4) del artículo 407 que configura una causal de disolución de una sociedad cuando las pérdidas han reducido el patrimonio neto a cantidad inferior a la tercera parte del capital pagado, salvo que sean resarcidas o que el capital pagado sea aumentado o reducido en cuantía suficiente. En este caso concreto, una vez determinado el patrimonio neto, se reflejará de la forma más idónea y objetiva la verdadera situación económica de la sociedad, correspondiéndole al directorio, que es el órgano técnico de una sociedad anónima, convocar de inmediato a la Junta General de Accionistas y proponerle la adopción de las medidas correctivas más convenientes y factibles según las circunstancias particulares y el contexto en el que dicha sociedad desarrolla sus actividades, pero si fuere el caso que la Junta General no se reuniera por no contarse con el quórum calificado requerido, o que una vez reunida no adopte el acuerdo de disolución o las medidas que correspondan, cualquier socio, administrador, director o el gerente, puede solicitar al Juez del domicilio social, que declare la disolución de la sociedad, conforme lo establece el artículo 409 de la LGS.

Respecto al valor empresa, que es un elemento nuevo de reciente introducción en la praxis societaria, y aún tenuemente comentado en la doctrina jurídica, este está estrechamente vinculado con el capital social y el patrimonio neto, y a diferencia de estos últimos, no existe ninguna regulación o mención directa en la LGS, y el comentario acerca de su contenido será precisamente la motivación del presente trabajo introductorio, siempre con cargo a un mayor análisis posterior.

\section{EL VALOR EMPRESA Y SU RECONOCIMIENTO EN LA LGS}

El valor empresa, es un concepto cuya utilidad es innegable sobre todo en un contexto en el cual las empresas en general necesitan ser replanteadas para ganar competitividad, lo cual exige una permanente valorización técnica, razón por la cual, a nuestro modo de ver, merecería al menos ser mencionado o reconocido en la LGS.

Siguiendo el orden de ideas del planteamiento introductorio, ya hemos visto que tenemos en

3 Parte final del quinto párrafo del artículo 200 de la LGS, relativo al reembolso del valor de las acciones. 
la LGS, de un lado el patrimonio social que es la universalidad de activos y pasivos, de otro, el capital social que es una cifra determinada en el pacto social y en el estatuto que se integra por los aportes de los accionistas, y que está dividido y representado en partes alícuotas cada una de las cuales tiene un valor nominal, también determinado, y finalmente tenemos el patrimonio neto que es una cifra a la que se llega después de un examen de los estados financieros, a través de los cuales como bien advierte el artículo 221 de la LGS, de estos documentos debe resultar con claridad y precisión, la situación económica y financiera de la sociedad, cifra que, como ya hemos mencionado, dividida entre el número de acciones nos dará el valor en libros de las acciones. Existe sin embargo un concepto o elemento nuevo que es el denominado valor empresa, el cual resultará de adicionarle al patrimonio neto un conjunto de elementos extra-contables que no se muestran en los estados financieros y que sin embargo constituyen los activos más valiosos a los cuales se les denomina genéricamente como "intangibles", comprendiendo estos entre otros, el equipo de administración y gerencia, el portafolio de clientes, la capacidad de la empresa para generar flujos futuros, la apreciación acerca de su lealtad, los canales de distribución, los procedimientos tecnológicos, el know how, la clasificación crediticia, la base de datos, los software patentados, las redes de comunicación, el goodwill, la moral del personal, la cultura empresarial, y los signos distintivos con los que cuenta, tales como las marcas, patentes, lemas, diseños, nombres comerciales etc., que si bien pueden estar contabilizados como activos, sus valores no son los que corresponden a los valores del mercado. Una vez obtenido el valor empresa, este se dividirá entre el número de acciones y nos dará un valor unitario de las acciones que servirá de base para una eventual negociación de las mismas, o para la evaluación de posibles reorganizaciones societarias en cualquiera de las modalidades reguladas por la LGS.

El valor empresa, así obtenido, no debería entenderse como un valor absoluto y definitivo, sino más bien como una estimación objetiva sustentable y demostrable que fortalecerá una posición negociadora, ni tampoco debería entenderse como un resultado final sino, como un punto de partida para iniciar una negociación. Asimismo, no debe confundirse el valor empresa con el precio, que es la cantidad en la que el vendedor y el comprador acuerdan realizar una operación de compra-venta de un negocio o de sus acciones, suma que no tiene que coincidir exactamente con el valor que se ha determinado en la valorización y al que se llegará de consuno, entre las partes.

Hechas las necesarias precisiones, advertimos que no se ha regulado en la LGS una definición de valor empresa, y menos aún respecto a cuales son sus componentes, temas que en principio nos parece que escaparían a los alcances de una normativa societaria de carácter general, pero sí nos parecería necesario reconocer el concepto de valor empresa al cual se llega partiendo necesariamente del patrimonio neto. Es nuestra opinión que el solo hecho de reconocerlo o mencionarlo en la LGS contribuirá a la seguridad jurídica en procesos de fusiones, escisiones o de adquisiciones, procesos en los cuales, el valor de las empresas participantes tiene una especial trascendencia. Podría sostenerse además que la omisión del reconocimiento por la LGS puede generar problemas de tecnicidad, en tanto solo los especialistas estarán en condiciones de entender el concepto que subyace, y posiblemente podría generar errores en la aplicación de los elementos o variables que tengan este componente de valor.

Es importante destacar sin embargo, que no obstante que no hay un reconocimiento o mención expresa al valor empresa, a lo largo de la LGS si hay determinadas situaciones en las que se requiere de su determinación, para obtener un valor unitario por acción o participación, siendo tales situaciones las siguientes:

a) Dentro de los procesos de fusión, es necesario establecer una relación de canje la cual se fija teniendo en cuenta el valor actualizado o ajustado de las acciones partiendo de un informe de valorización de la empresa, la cual, determinará la cantidad de acciones o participaciones que le corresponderá a cada socio.

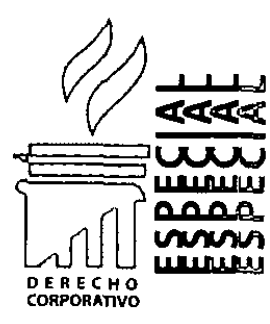


Al efecto, el artículo 347 de la LGS establece que el proyecto de fusión debe contener los criterios de valorización empleados para la determinación de la relación de canje entre las respectivas acciones o participaciones de las sociedades participantes en la fusión, lo cual, supone que cada una de las empresas que participará en el proceso de fusión debe ser valorizada, para lo cual no se ha previsto ningún criterio que oriente dicha actividad, y menos aún la metodología a emplearse.

En el caso de la legislación societaria española, la Ley de Sociedades Anónimas en cambio si ha previsto en el artículo 235 literal b), que el tipo de canje se desarrollará sobre la base del valor real del patrimonio social, y la compensación complementaria en dinero que, en su caso, se prevea, lo cual implica la necesidad de calcular el "valor real del patrimonio", regulación que se diferencia de la libertad con la que nuestra legislación permite que se fije el tipo de valorización.

b) De forma similar a lo que ocurre en las fusiones, en el artículo 372 de la LGS se regula que el proyecto de escisión debe contener la relación de canje entre las respectivas acciones o participaciones de las sociedades que participan en la escisión; lo que supone que sea necesario también, que cada una sea objeto de un proceso de valorización.

c) Para el ejercicio del derecho de adquisición preferente en las sociedades anónimas cerradas, el artículo 237 de la LGS establece que el accionista que se proponga transferir total o parcialmente sus acciones a otro accionista o a terceros, debe comunicarlo a la sociedad mediante carta dirigida al gerente general, quien lo pondrá en conocimiento de los demás accionistas dentro de los diez días siguientes, para que dentro del plazo de treinta días puedan ejercer el derecho de adquisición preferente a prorrata de su participación en el capital, debiendo incluir en la comunicación el nombre del posible comprador y si es persona jurídica el de sus principales socios o accionistas, el número y clase de las acciones que desea transferir, el precio y demás condiciones de la transferencia. También se ha regulado dentro del artículo 237 que en caso de transferencias a título oneroso distintas a la compra-venta, o a título gratuito, el precio de adquisición será fijado por acuerdos entre las partes o por el mecanismo de valorización que establezca el estatuto, y en su defecto por el Juez.

d) Asimismo, en el caso de las sociedades anónimas cerradas, el artículo 240 de la LGS permite en el pacto social o en el estatuto se establezca que en caso de trasmisión de las acciones por sucesión hereditaria, los demás accionistas tendrán derecho a adquirir dentro del plazo que uno u otro determine, las acciones del accionista fallecido por su valor a la fecha del fallecimiento, y si fueran varios los accionistas que quisieran adquirir estas acciones, se distribuirán entre todos a prorrata de su participación en el capital social. Lo interesante de esta regulación radica en el hecho que, en caso de existir discrepancia en el valor de la acción se recurrirá a tres peritos nombrados, uno por cada parte y un tercero por los otros dos, y si no se lograra fijar el precio por los peritos, el valor de la acción lo fijará el Juez por el proceso sumarísimo.

e) En el caso de las Sociedades Comerciales de Responsabilidad Limitada, en el artículo 291 de la LGS se prevé que el socio que se proponga transferir sus participaciones sociales a persona extraña a la sociedad, debe comunicarlo por escrito dirigido al gerente, quien lo pondrá en conocimiento de los socios en el plazo de diez días, a efectos que puedan manifestar su voluntad de compra dentro de los treinta días siguientes a la notificación, lo que constituye un derecho de adquisición preferente, y si fueran varios los interesados, se distribuirá entre todos ellos a prorrata de sus respectivas participaciones. Lo interesante de esta regulación es que para el ejercicio del derecho de los socios, el precio de venta en caso de discrepancia, será fijado por tres peritos nombrados uno por cada parte, y un tercero nombrado por los otros dos, o si esto no se logra, por el Juez a través de un proceso sumarísimo. 
f) En la transmisión de las participaciones por sucesión en la sociedad comercial de responsabilidad limitada, conforme el artículo 290 de la LGS se puede establecer en el estatuto, que los otros socios tengan derecho a adquirir dentro del plazo que aquel determine las participaciones del socio fallecido, según el mecanismo de valorización que el estatuto señale, y si se fueran varios los socios que quisieran adquirir esas participaciones, se distribuirán entre todos a prorrata de sus respectivas partes sociales.

g) La última situación que advertimos es la referida al ejercicio del derecho de separación del accionista, que como se sabe, es un derecho esencial de los accionistas que les permite retirarse de la sociedad en determinados supuestos. Sobre el particular, Amico Anaya ${ }^{44}$ señala que: "es un derecho intangible que tienen los accionistas ausentes o disidentes para apartarse de la sociedad cuando la asamblea decide una cuestión que altera profundamente su situación dentro de ella".

h) Los supuestos en que procede el derecho de separación son: 1. El cambio del objeto social; 2. El traslado del domicilio al extranjero; 3. La creación de limitaciones a la transmisibilidad de las acciones o la modificación de las existentes; y, 4. En los demás casos que lo establezca la ley o el estatuto, y que entre otros son los casos de los artículos 356 y 385 relativos a las fusiones y escisiones, respectivamente.

Como requisito para el ejercicio del mencionado derecho, se establece que sólo pueden ejercer el derecho de separación los accionistas que en la junta hubiesen hecho constar en acta su oposición al acuerdo, los ausentes, los que hayan sido ilegítimamente privados de emitir su voto y los titulares de acciones sin derecho a voto.
Lo trascendente para este tema, es el valor que se asigna a las acciones de aquellos quienes hacen uso del derecho de separación. Así la LGS señala que las acciones se reembolsarán en primer lugar al valor que acuerden el accionista y la sociedad, y de no haber acuerdo, las acciones que tengan cotización en Bolsa se reembolsarán al valor de su cotización media ponderada del último semestre, y si no tuvieran cotización, al valor en libros, al último día del mes anterior al de la fecha del ejercicio del derecho de separación, siendo el valor en libros como ya lo hemos comentado, el que resulte de dividir el patrimonio neto entre el número total de acciones, y el que será el valor máximo a pagar incluso en los supuestos que se haya fijado el valor de reembolso, de común acuerdo.

\section{CRITERIOS O MÉTODOS PARA LA VALORIZACION DE EMPRESAS Y SU REGULACIÓN POR LA LGS}

Reconocer el valor empresa como un valor distinto al patrimonio neto, conlleva por lo menos conocer los diferentes criterios o métodos que se utilizan en la praxis societaria para atribuirle un determinado valor a una empresa, lo cual implica preguntarse hasta qué nivel de detalle debería llegar la LGS, sobre todo cuando existen disciplinas especializadas que se ocupan de este tema.

El hecho de atribuir un valor a una empresa significa proceder de acuerdo con unos principios generales de actuación tomando también en consideración los aspectos particulares que inciden en la misma, ya sean estructurales o coyunturales. Conviene señalar que el concepto valor es objetivo, y no debe ser tomado en el sentido de precio, que se definirá en función de otros factores con la presión de la oferta y de la demanda, la situación económica en general, la coyuntura etc., ligados a la operación de compra-venta u otra modalidad de transferencia.

4 AMICO ANAYA, Mateo, Derechos y obligaciones del Accionista: Algunas aproximaciones. En: Tratado de Derecho Mercantil, Tomo I Derecho Societario, Gaceta Jurídica, Lima, Agosto, 2003, p. 464. 
En cuanto a los principios generales aplicables a cualquier supuesto de valorización de sociedades, nos encontramos entre otros con los siguientes:

1. Una definición temporal, ya que toda valorización debe venir referida a una fecha concreta, teniéndose presente, que valorar es definir un valor monetario a la realidad de una empresa. Tanto la unidad de valor o moneda, como la realidad misma de la empresa son mutantes en el tiempo, incluso a plazo inmediato.

2. La objetividad, ya que la valorización debe ser el resultado de la aplicación de criterios y objetivos. Para garantizar esta objetividad se acude generalmente a un experto independiente.

3. La unidad de criterio, ya que la técnica de valorización no debe modificarse durante el trabajo correspondiente. Eso no implica que no se pueda utilizar simultáneamente más de un criterio para una valorización concreta.

4. La apreciación del futuro, ya que el valor de una empresa debe basarse tanto en la situación patrimonial en el momento de la valorización, como en la evolución futura que cabe esperar en ella. Esta apreciación de futuro implica un fuerte componente de riesgo, que hay que minimizar y cuantificar en la medida de lo posible.

5. La prudencia valorativa, en razón a que los criterios aplicados deben procurar mantener los valores utilizados en la valorización, dentro de los entornos de mayor probabilidad o, en caso de que se desconozca esta, en la posición menos favorable, y en dicha estimación se debe evitar cuidadosamente cualquier concesión al optimismo $o$ al pesimismo, por que la posición menos favorable a la que se refiere el párrafo anterior, no debe constituir en si misma una posición pesimista. De este modo se contribuye a minimizar el riesgo en las estimaciones tanto de futuro (proyección de ventas, por ejemplo) como de presente (estimación de un valor sustancial, por ejemplo).

Respecto a la utilidad en la valorización de empresas, existen fundamentalmente dos, a saber:

a) De utilidad pública, por procesos de nacionalizaciones, expropiaciones o privatizaciones.

b) De utilidad privada, por fusión y absorciones, escisiones, compra-venta de empresas, garantías bancarias o para obtener el valor bursátil.

Asimismo, en las teorías financieras especializadas se distinguen dos clases de valor empresa, el valor objetivo, que es el que se obtiene a través de la aplicación de la técnica de valorización y que expresa en términos comunes el valor de la empresa sin considerar los intereses propios de los agentes que intervienen en las operaciones, y el valor subjetivo que en cambio si tiene un componente que lo condiciona, que es el interés propio de los sujetos que la hacen valorizar.

En cuanto a los criterios de valorización de empresas, o los métodos que se aplican, estos son variados, y/o múltiples, y cada uno puede responder a determinadas circunstancias y situaciones, o estar influenciado en razón a quienes lo realizan, o cual es su finalidad, los cuales pueden arrojar resultados diferentes cuya aplicación depende de la finalidad específica para la cual se realiza y que en todo caso estos resultados no son necesariamente excluyentes entre sí, sino que eventualmente pueden complementarse.

Cada uno de estos criterios o metodologías de valorización tiene características y finalidades específicas, no pudiendo ser materia del presente trabajo entrar en el análisis de cada una de ellas, pero sí corresponde al menos resumirlas en base a las fuentes utilizadas y en ese sentido, en teoría financiera se distingue entre los métodos patrimoniales dentro de los cuales está el valor contable, el valor contable ajustado, el valor de liquidación y el valor sustancial, métodos 
mixtos o compuestos, métodos comparativos y métodos de valorización por descuentos de flujos.

En función a lo anteriormente expuesto de manera muy concreta y resumida corresponde ya formularnos la interrogante, acerca de sí se debe o no regular los criterios de valorización de empresas en la LGS, y frente a dicha interrogante encontramos tres posiciones:

a) Una primera posición constituida por quienes opinan que es preferible que no se incluya en la Ley ningún criterio o metodología para la valorización de empresas, por lo cual, se dejará a las propias sociedades que intervengan en las distintas operaciones, determinar libremente cuáles serán los criterios y la metodología que se debe aplicar para determinar el valor empresa, prevaleciendo en consecuencia a la autonomía de voluntad. A favor de esta opinión se encuentra el hecho de que ello permitirá a las empresas, atendiendo a las consideraciones particulares de cada acto, que puedan decidir los métodos o criterios que utilicen para la valorización de empresas de la forma más conveniente a los intereses de ellos.

En el caso de la fusión de empresas por ejemplo, Luz Israel Llave y Alfredo Filomeno Ramírez ${ }^{5}$, señalan sobre este aspecto: "(...) no obstante, consideramos que resulta igualmente válido que la LGS adopte una fórmula que permita a los administradores, y posteriormente a los socios, aprobar una relación de canje que no necesariamente responda a un criterio preestablecido por el legislador, sino que se fije de acuerdo a la autonomía de la voluntad, sin perjuicio de que, en la mayoría de casos, sea el valor real del patrimonio de las sociedades el factor determinante para establecer la relación de canje. Se debe tomar en cuenta, por cierto, que una empresa puede valorizarse desde distintas perspectivas y siguiendo criterios diversos, pudiéndose determinar la relación de canje en función de un valor liquidativo, de empresa en funcionamiento, por capitalización bursátil, valor en venta, valor en función del rendimiento o del cash flow, etc. En ese sentido, consideramos conveniente que la LGS haya establecido un sistema lo suficientemente amplio y abierto como para incluir distintos métodos de determinación de la relación de canje, los cuales evidentemente, deben ajustarse a principios de razonabilidad y transparencia que garanticen un reparto equitativo de las acciones o participaciones que se deban emitir como consecuencia de la fusión".

Esta libertad de fijar los criterios para la valorización de la sociedad bajo un marco legal en el que no se fija ningún criterio, que en principio compartimos, puede sin embargo, generar algunas distorsiones que afecten los intereses de una o más de las partes interesadas. En efecto, pensemos para seguir en el ejemplo de la fusión, lo que podría ocurrir si en la valorización se decide por criterios que no son los adecuados para acercase objetivamente al valor real de la empresa, como sucedería si se aplica la metodología o criterios de sociedad en liquidación, para evaluar la sociedad Alfa, que es una empresa en marcha, con capacidad de generar flujos positivos de manera constante en el futuro, mientras que en la sociedad Beta se utiliza también sustentada en la autonomía de voluntad, un método basado en el descuento de flujos. Como puede advertirse esa valorización generará distorsiones en la valorización que sin duda afectará a los accionistas de la sociedad Alfa, en la relación de canje, y por consiguiente en su participación en la empresa, generando una situación no deseada, en especial, si ello ha ocurrido en perjuicio de socios o accionistas que han debido atenerse a la decisión de la mayoría.

b) Una segunda posición es la de regular en la LGS los criterios que se deben usar para va-

5 ISRAEL LLAVE, LUz y FILOMENOS RAMIREZ, Alfredo, La Fusión y la Escisión en la nueva Ley General de Sociedades: Algunas aproximaciones. En: Tratado de Derecho Mercantil, Ob. Cit., p. 1159. 
lorizar las sociedades, en la forma como por ejemplo se han regulado estos criterios en el Reglamento de Oferta Pública de Adquisición de Compra de Valores por Exclusión, aprobado por Resolución CONASEV No. 9-2006-EF/94.10, a través del cual se regula las OPA's con el propósito de garantizar que cuando se produzca una adquisición o incremento de participación significativa, todos los accionistas puedan participar en la prima de control que con tal motivo se pueda ofrecer. En el artículo 50 de esta disposición, se regula que la valorización se debe realizar de acuerdo con las prácticas aceptadas internacionalmente y considerando, cuando menos, los siguientes criterios debidamente justificados: Valor contable de la sociedad, Valor de liquidación de la sociedad, Valor de la sociedad como negocio en marcha, precio promedio ponderado de los valores durante el semestre inmediatamente anterior a la fecha de la ocurrencia de la causal que genera la obligación de llevar a cabo la oferta; y si se hubiese formulado alguna OPA dentro de los doce meses previos a la fecha de la ocurrencia de la causal que genere la obligación de llevar a cabo la oferta, la contraprestación ofrecida en tal oportunidad.

Se precisa que luego de aplicar a todos los criterios antes mencionados o de sustentar la imposibilidad de su utilización, la entidad valorizadora señalará el precio a través del criterio que, a su juicio, resulte más adecuado para el caso concreto.

Esta disposición dirigida a las empresas valorizadoras ha permitido en el caso de la OPA's reducir la parcialidad que puede influenciar el proceso valorativo, en tanto obliga a considerar el valor desde varias perspectivas, y luego hacer un análisis sustentado de las razones que conducen a determinar un valor especifico.

En el caso de la legislación española, a través de la Ley de Sociedades Anónimas, se señala en su artículo 235 que para establecer la relación de canje en las fusiones, este se debe determinar sobre la base del valor real del patrimonio social, y la compensación complementaria en dinero que, en su caso, se prevea. Asi, es razonable establecer criterios que lo hagan razonable, y por sobre todo, que obligue a justificar el valor determinado como consecuencia de la aplicación de los criterios preestablecidos. Esta limitación a la autonomia de la voluntad, tendrá como sustento la cautela del interés de las partes que participan en cualquiera de los actos que requieran de una valorización de la sociedad, evitando distorsiones que les puedan perjudicar sus derechos.

Para quienes apoyan esta posición, los criterios que se señalen en la Ley, únicamente deberían ser obligatorios para aquellos actos en los que es indispensable defender los intereses de alguna de las partes, como se distingue en la fusión, en la escisión, en la adquisición preferente, en las nacionalizaciones, o expropiaciones, más no en otros casos para los cuales servirán a forma de referencia, pero no se podrá obligar a aplicarlos, como las valorizaciones que se realizan para evaluaciones internas de negocio, u operaciones de compra-venta en las que el precio de venta es determinado por consenso entre vendedor y comprador.

c) Una tercera posición y más extrema aún, la cual consiste en que en la LGS se señale cuál es la metodología concreta que debería aplicarse para la valorización de empresas. Sin embargo, como se ha explicado anteriormente, las múltiples metodologias que existen responden a diversas coyunturas, $y$ pueden originar que en determinadas circunstancias no sea posible aplicar alguna que es la idónea para realizar el mismo proceso en otra sociedad.

Retomando el ejemplo de la fusión, pensemos en una empresa sin actividad que participa en una fusión en calidad de absorbida, por otra que se encuentra en marcha, y que por lo tanto es capaz de generar flujos. Si aplicáramos a ambas la metodología de liquidación se perjudicaría a la empresa absorbente, mientras que si aplicara la de des- 
cuento de flujos, se castigaría a la absorbida. Por ello es necesario aplicar una fórmula que permita que las evaluaciones puedan ser amoldadas de acuerdo a las circunstancias particulares, pero asegurándose de dotar de terminadas seguridades mínimas para los intervinientes, tales como: i) la necesidad de un informe de valorización realizado de acuerdo a las prácticas contables y financieras aceptadas, ii) la aplicación de criterios mínimos: valor contable, valor de liquidación, valor de empresa en marcha, y promedio de cotizaciones (cuando cotice en bolsa); iii) la necesidad de justificar los casos en que no sea posible aplicar alguno de los mencionados criterios; iv) la obligación de sustentar el valor determinado en el caso concreto.

\section{PROPUESTA DE ARTículo SUSTITUTORIO}

Luego de la presentación del tema, tal y como se ofreció, corresponde proponer un proyecto del artículo 31 de la LGS que incorpore los elementos anteriormente descritos y que consideramos están estrechamente vinculados.

\section{Artículo 31 de la LGS}

"El patrimonio social responde por las obligaciones de la sóciedad sin perjuicio de la responsabilidád personal.'́le los socios en aquellas formas sócietarías que así lo contemplen.

El capital social, és fijado voluntariamente por los socios, /salvó las excépciones establecidas por leyes especiáles y dividido en parte alícuota estábléce el valor nominal de las cuotas, acciónes, participaciones y derechos.

El-patrimonio neto--se-obtendrá después de restarle al monto de los activos, los pasivos-exigibles,-y-una-vez-dividido en partes alícuotas establece el valor en libros de las cuotas, acciones, participaciones y derechos.

El valor empresa, se obtendrá adicionalmente al patrimonio néto, los intangibles y la cifra obtenida, una vèz dividida en partes alículotaś establece-el valor-de mercado de las cuotas, acciones, participaciones y derechos".

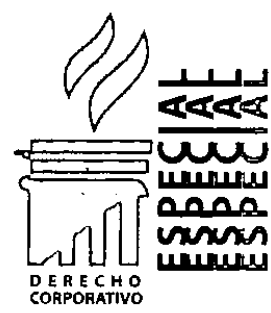

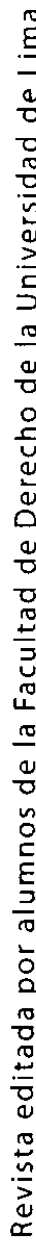

